\title{
Cold Agglutinin-Mediated Autoimmune Hemolytic Anemia in Association with Antiphospholipid Syndrome
}

\author{
Ram Gelman $^{a}$ Fadi Kharouf ${ }^{b}$ Yuval Ishay ${ }^{c}$ Alexander Gural ${ }^{d}$ \\ ${ }^{a}$ Department of Medicine, Hebrew University-Hadassah Medical Center, Jerusalem, Israel; ${ }^{b}$ Rheumatology \\ Unit, Department of Medicine, Hebrew University-Hadassah Medical Center, Jerusalem, Israel; ' Department of \\ Gastroenterology and Liver Diseases, Hebrew University-Hadassah Medical Center, Jerusalem, Israel; ${ }^{\mathrm{d} D e p a r t m e n t}$ \\ of Hematology and Transfusion Medicine, Hebrew University-Hadassah Medical Center, Jerusalem, Israel
}

\section{Keywords}

Cold agglutinin · Hemolytic anemia · Antiphospholipid syndrome $\cdot$ Complement activation

\section{Abstract}

Antiphospholipid syndrome and cold agglutinin-mediated autoimmune hemolytic anemia are 2 distinct immune-mediated hematologic disorders. While no clear association exists between these 2 entities, complement activation is known to occur in both of them. Herein, we report a unique case of cold agglutinin hemolytic anemia in a patient with a known primary antiphospholipid syndrome.

(C) 2021 The Author(s)

Published by S. Karger AG, Basel

\section{Introduction}

Antiphospholipid syndrome (APLS) is an acquired antibody-mediated hypercoagulability state characterized by recurrent vascular thrombotic events and/or obstetric morbidity, in the presence of antiphospholipid antibodies (aPL) [1]. APLS can occur either primarily or in the context of other autoimmune diseases. In systemic lupus erythematosus (SLE), the prevalence of aPL can reach $30 \%$ [2].

Autoimmune hemolytic anemias (AIHA) are a group of rare disorders in which hemolysis occurs due to autoantibodies directed against red blood cell surface antigens [3]. AIHA can be classified according to the thermal characteristics of the causative antibody into warm and cold types. The majority of patients with AIHA suffer from immunoglobulin G (IgG)-mediated warm-type AIHA [4]. Chronic cold-reactive AIHA accounts for $25 \%$ of all AIHA cases and is mediated by cold agglutinin (CA) antibodies, mostly M-type immunoglobulins (IgM). In one cohort, warm-type IgG-mediated AIHA was found to occur in $10 \%$ of APLS patients [5].

Here, we present a case of CA IgM-mediated AIHA in a patient with APLS. To the best of our knowledge, such an association has not been described thus far.

\section{Case Presentation}

A 53-year-old woman, a habitual heavy smoker, presented to her primary care physician with a 2 -week history of gradually worsening fatigue and bilateral knee pain. Laboratory studies revealed severe anemia (hemoglobin $[\mathrm{Hb}]$ of $6.4 \mathrm{~g} / \mathrm{dL}$ ). The pa- karger@karger.com www.karger.com/aha

Karger $\stackrel{\text { ' }}{=}$ BOPEN ACCESS
(C) 2021 The Author(s)

Published by S. Karger AG, Basel

This is an Open Access article licensed under the Creative Commons Attribution-NonCommercial-4.0 International License (CC BY-NC) (http://www.karger.com/Services/OpenAccessLicense), applicable to the online version of the article only. Usage and distribution for commercial purposes requires written permission.
Correspondence to:

Ram Gelman, ram.gelman@gmail.com 
tient was referred to the emergency department (ED) and hospitalized to the medical ward between September 13, 2020 and September 22, 2020. During this period the weather was warm with the temperature ranging between 23 and $32^{\circ} \mathrm{C}$. She reported a single episode of low-grade fever $\left(37.5^{\circ} \mathrm{C}\right)$, and a mild weight loss over the preceding months. No gross external bleeding was noted, and a detailed review of organ systems was otherwise unremarkable.

The patient's past medical record was significant for APLS, diagnosed following 6 miscarriages and an ischemic cerebrovascular accident, combined with positive aPL. She was maintained on warfarin therapy, with therapeutic INR values. Furthermore, 2 years before current hospitalization, she developed pancytopenia, initially identified during routine bloodwork, with white blood cell counts of 3,700-3,800 U/L (normal range 4,500-11,000 U/L), Hb of $9.1-10.0 \mathrm{~g} / \mathrm{dL}$ (normal range 12.0-16.0 g/dL), and platelet counts of 43,000-88,000 U/L (normal range 150,000-450,000 $\mathrm{U} / \mathrm{L})$. Transient hepatocellular enzymes elevations, up to twice the normal values, and mild splenomegaly of $15.5 \mathrm{~cm}$ were also reported.

Upon arrival to the ED, the patient was afebrile but slightly tachycardic, with normal blood pressure and oxygen saturation. The spleen was palpated $2 \mathrm{~cm}$ below the costal margin, with no other abnormalities on physical examination.

Initial laboratory workup showed pancytopenia, elevated lactate dehydrogenase, and low haptoglobin levels. Coagulation studies revealed a prolonged partial thromboplastin time, with therapeutic INR. Electrolytes, creatinine, liver enzymes, C-reactive protein, iron, and vitamin B12 levels were all within normal limits. A mild folic acid deficiency was found (See Table 1 for summary of the lab results on admission). Urinalysis was unremarkable, and a 24 -h urinary protein collection ruled out proteinuria. Blood smear demonstrated spherocytosis and red cell fragments, compatible with hemolysis. Direct antiglobulin test (DAT) was negative for the presence of IgM and IgG, and positive for $\mathrm{C}_{3} \mathrm{~d}$ [IH-1000/Biorad].

A chest X-ray was normal and computed tomography scan of the chest, abdomen, and pelvis demonstrated splenomegaly of 19 $\mathrm{cm}$, with no further abnormalities. Microbiologic, serologic, and polymerase chain reaction tests were negative for cytomegalovirus, Epstein-Barr virus (QS 5/ABI), and Mycoplasma pneumoniae (RG Q/Qiagen).

Immune serologies demonstrated elevated aPL and IgM levels (Sysmex c5100; Alegria/Orgentec; BN ProSpec/Siemens). ANA, rheumatoid factor, anti-neutrophil cytoplasmic antibodies, and cryoglobulins were negative (IF/Biorad; Atellica/Siemens; Alegria/ Orgentec; manual). Complement levels were low (BN ProSpec/ Siemens) (See Table 2 for summary of the patient's immune workup during hospitalization). Serum protein electrophoresis was positive for monoclonal IgM, with mildly elevated levels of both $\kappa$ and $\lambda$ free light chains and a normal light chain ratio (Hydrasys/ Sebia). Serum protein immunofixation was positive for IgM/ $/ \mathrm{Pe}$ ripheral blood flow cytometry was unremarkable (Navios EX/ Beckman), and a bone marrow biopsy revealed abundance of red cell precursors with a shift to the left and normal myeloid maturation; several clusters of small lymphoid cells, some staining positive for $\mathrm{CD} 20+$ and some for CD3+ were also present. Polymerase chain reaction for monoclonal $\mathrm{B}$-cell gene rearrangement was negative (TC 2720/ABI), effectively ruling out the presence of a lymphoproliferative process.
Table 1. The patient's laboratory workup upon admission to the hospital

\begin{tabular}{lll}
\hline Lab parameter & Patient & Normal range \\
\hline WBC count & $2,400 \mathrm{U} / \mathrm{L}$ & $4,050-11,840 \mathrm{U} / \mathrm{L}$ \\
Hb & $6.9 \mathrm{~g} / \mathrm{dL}$ & $12.4-16.1 \mathrm{~g} / \mathrm{dL}$ \\
PLT count & $94,000 \mathrm{U} / \mathrm{L}$ & $203,000-445,000 \mathrm{U} / \mathrm{L}$ \\
Potassium & $3.6 \mathrm{mmol} / \mathrm{L}$ & $3.5-5.1 \mathrm{mmol} / \mathrm{L}$ \\
Sodium & $138 \mathrm{mmol} / \mathrm{L}$ & $136-145 \mathrm{mmol} / \mathrm{L}$ \\
Creatinine & $66 \mu \mathrm{mol} / \mathrm{L}$ & $49-90 \mu \mathrm{mol} / \mathrm{L}$ \\
LDH & $294 \mathrm{U} / \mathrm{L}$ & $120-246 \mathrm{U} / \mathrm{L}$ \\
CRP & $0.75 \mathrm{mg} / \mathrm{dL}$ & $<0.5 \mathrm{mg} / \mathrm{dL}$ \\
Albumin & $42 \mathrm{~g} / \mathrm{L}$ & $32-48 \mathrm{~g} / \mathrm{L}$ \\
ALT & $14 \mathrm{U} / \mathrm{L}$ & $10-49 \mathrm{U} / \mathrm{L}$ \\
Alk. P & $68 \mathrm{U} / \mathrm{L}$ & $46-116 \mathrm{U} / \mathrm{L}$ \\
T. Bilirubin & $23.8 \mu \mathrm{mol} / \mathrm{L}$ & $5-21 \mu \mathrm{mol} / \mathrm{L}$ \\
INR & $2.66 \mathrm{ratio}$ & $0.9-1.2 \mathrm{ratio}$ \\
PTT & $53.5 \mathrm{~s}$ & $22.4-36.3 \mathrm{~s}$ \\
Iron & $66.0 \mu \mathrm{g} / \mathrm{L}$ & $50-170 \mu \mathrm{g} / \mathrm{L}$ \\
Transferrin & $196.2 \mathrm{mg} / \mathrm{dL}$ & $250-380 \mathrm{mg} / \mathrm{dL}$ \\
Ferritin & $83 \mathrm{ng} / \mathrm{mL}$ & $10-291 \mathrm{ng} / \mathrm{mL}$ \\
Total iron binding capacity & $249.17 \mathrm{mg} / \mathrm{L}$ & $250-380 \mathrm{mg} / \mathrm{L}$ \\
Vitamin B12 & $503 \mathrm{pg} / \mathrm{mL}$ & $211-911 \mathrm{pg} / \mathrm{mL}$ \\
Folic acid & $3.59 \mathrm{ng} / \mathrm{mL}$ & $>5.4 \mathrm{ng} / \mathrm{mL}$ \\
Haptoglobin & $3 \mathrm{mg} / \mathrm{L}$ & $30-200 \mathrm{mg} / \mathrm{L}$ \\
& &
\end{tabular}

Normal ranges refer to females. WBC, white blood cell; $\mathrm{Hb}$, hemoglobin; PLT, platelet count; LDH, lactate dehydrogenase; CRP, C-reactive protein; PTT, partial thromboplastin time.

Thus, the patient was diagnosed as suffering from IgM-mediated AIHA in association with APLS. While a short corticosteroid course has produced no benefit, her $\mathrm{Hb}$ levels remained stable throughout the hospitalization. The patient was discharged in a good condition for outpatient follow-up with supportive treatment including folate supplementation, and anticoagulation. Over the next 2 months, she was treated with 2 units of packed red blood cells on monthly outpatient follow-up visits, which led to gradual improvement in clinical symptoms and laboratory parameters. On her third outpatient visit, 3 months following discharge she had a white blood cell count of 4,400 U/L, Hb of $11.3 \mathrm{~g} / \mathrm{dL}$, and a platelet count of 70,000 U/L.

\section{Discussion}

In this case report we describe a unique combination of APLS and CA IgM-mediated AIHA, presenting as pancytopenia, DAT-positive hemolytic anemia, splenomegaly and low complement levels, without lymphadenopathy or evidence of clonal lympho-proliferation on bone marrow biopsy. CA IgM-mediated AIHA is a well-defined entity, where the relatively high thermal amplitude $\left(28-30^{\circ} \mathrm{C}\right)$ of CA allows erythrocyte binding by the anti- 
Table 2. The patient's immune workup during hospitalization

\begin{tabular}{lll}
\hline Lab parameter & Patient & Normal range \\
\hline IgA & $130.00 \mathrm{mg} / \mathrm{dL}$ & $70-400 \mathrm{mg} / \mathrm{dL}$ \\
IgM & $658.00 \mathrm{mg} / \mathrm{dL}$ & $40-230 \mathrm{mg} / \mathrm{dL}$ \\
IgG & $1,200.00 \mathrm{mg} / \mathrm{dL}$ & $700-1,700 \mathrm{mg} / \mathrm{dL}$ \\
ANA & Negative & \\
C $_{3}$ & $72.80 \mathrm{mg} / \mathrm{dL}$ & $90-180 \mathrm{mg} / \mathrm{dL}$ \\
C $_{4}$ & $4.46 \mathrm{mg} / \mathrm{dL}$ & $10-40 \mathrm{mg} / \mathrm{dL}$ \\
C-ANCA & $1.5 \mathrm{U} / \mathrm{mL}$ & $<10 \mathrm{U} / \mathrm{mL}$ \\
P-ANCA & $1.4 \mathrm{U} / \mathrm{mL}$ & $<5 \mathrm{U} / \mathrm{mL}$ \\
Rheumatoid factor & $9.8 \mathrm{IU} / \mathrm{mL}$ & $<15 \mathrm{IU} / \mathrm{mL}$ \\
Serum protein electrophoresis & Positive for para-protein & \\
Serum protein immunofixation & IgM/k & \\
Free chain kappa & $52.5 \mathrm{mg} / \mathrm{L}$ & $6.7-22.4 \mathrm{mg} / \mathrm{L}$ \\
Free chain lambda & $41.1 \mathrm{mg} / \mathrm{L}$ & $8.3-27 \mathrm{mg} / \mathrm{L}$ \\
Kappa/lambda ratio & 1.28 & $0.31-1.56$ \\
Circulating anticoagulants & Positive & $\leq 1.4$ \\
Circulating anticoagulants ratio & 3.15 & $\leq 1.35$ \\
Dillute Russell's viper venom time ratio & 2.62 & $<7 \mathrm{U} / \mathrm{mL}$ \\
Anti-cardiolipin IgM & $74.8 \mathrm{U} / \mathrm{mL}$ & $<10 \mathrm{U} / \mathrm{mL}$ \\
Anti-cardiolipin IgG & $67.9 \mathrm{U} / \mathrm{mL}$ & $<5 \mathrm{U} / \mathrm{mL}$ \\
Anti-b2-glycoprotein IgM & $60.9 \mathrm{U} / \mathrm{mL}$ & $<5 \mathrm{U} / \mathrm{mL}$ \\
Anti-b2-glycoprotein IgG & $47.2 \mathrm{U} / \mathrm{mL}$ & \\
Cryoglobulin & Negative & \\
\hline
\end{tabular}

Normal ranges refer to females. IgM, immunoglobulin M; IgG, immunoglobulin G; ANCA, anti-neutrophil cytoplasmic antibodies.

bodies, and consequent agglutination during passage through the peripheral circulation [6]. IgM binds $\mathrm{C}_{1}$ on the red cell membrane, causing activation of the classical complement pathway. Once back to the body core, CA disassociates from the erythrocytes, while $\mathrm{C}_{3} \mathrm{~b}$ (further cleaved to $\mathrm{C}_{3} \mathrm{~d}$ ) remains bound, resulting in a positive DAT for $\mathrm{C}_{3} \mathrm{~d}$ and, in the majority of cases, negative for IgM and IgG [7]. CA-AIHA may appear as 1 of 2 entities - a primary disorder called cold agglutinin disease (CAD) or a secondary syndrome [7]. CAD has been established as a clonal lymphoproliferative disorder of the bone marrow [6]. The secondary CA syndrome (CAS) is a CA-mediated disorder, occasionally arising as a complication of certain infections, and possibly malignancies. Most commonly, CAS has been described in association with $M$. pneumoniae, Epstein-Barr virus and cytomegalovirus infections. While CA-AIHA has been reported in SLE [7], the prevalence of autoimmune diseases in CA-AIHA remains low [8].

While various hematologic abnormalities may occur in association with APLS, the incidence of warm-type AIHA in patients with APLS, is relatively low [9]. In the largest cohort of APLS patients, AIHA was seen in only
$6.6 \%$ of the cases [10]. A higher incidence of $10.4 \%$ was described in a later cohort of 308 patients [5]. Leukopenia, on the other hand, appears more frequently in APLS patients with SLE [10].

Hypocomplementemia is common in patients with primary APLS, reflecting complement activation and consumption [11]. Several mechanisms by which complement activation in APLS patients contributes to thrombotic events have been suggested [12]. The hemolytic process in CA-AIHA is completely complement-dependent [13]. The primary mechanism is activation of the classical complement pathway and extravascular hemolysis [6], though terminal complement cascade activation and intravascular hemolysis also exist in certain cases. The persistent complement activation and consumption cause low levels of $\mathrm{C}_{3}$ and $\mathrm{C}_{4}$ in CAD patients [14]. Novel complement-targeted therapeutics are currently under investigation for the treatment of both CA-AIHA and APLS $[6,12,13,15]$.

While splenic infarcts remain a known complication of thrombotic events in APLS, splenomegaly is rare and tends to be secondary to other disease manifestations, such as portal vein thrombosis [8]. The prevalence of he- 
patic pathologies in APLS is very low $(<1 \%)$. These include Budd-Chiari syndrome and thrombosis of smaller hepatic venules [10]. Erythrocyte sequestration was found to occur in the liver and spleen in CA-AIHA [16]. To the best of our knowledge, no hepatic or splenic disturbances were yet associated with primary CAD.

Besides the choice of a therapeutic strategy, an important concern in our patient remains a possible presence of a lymphoproliferative disease, despite a negative bone marrow biopsy. While some reports have suggested an association between APLS and hematological malignancies, the relation remains elusive [17]. CAD, on the other hand, is highly associated with bone marrow lymphoproliferative disorders, confirmed by immunohistochemistry in as many as $75 \%$ of the patients [18]. While spleen biopsy was not undertaken due to the procedural risk [17], the likelihood of a spleen-limited lymphoproliferative process remains exceedingly low. With a limited follow-up period on an outpatient basis so far, the patient has remained stable, without evidence of progression and without clinical symptoms requiring intervention.
In summary, we present here a previously unreported combination of 2 immune-mediated diseases, CA-AIHA and APLS. Further reports are required to discern a possible etiological association between these 2 entities, and to consider therapies targeting the common underlying process.

\section{Statement of Ethics}

Written informed consent was obtained from the patient for publication of this case report.

\section{Conflict of Interest Statement}

The authors have no conflicts of interest to declare.

\section{Author Contributions}

All authors made a substantial contribution to the case report and approved the final version of the manuscript.

\section{References}

1 Cervera R. Antiphospholipid syndrome. Thromb Res. 2017;151(Suppl 1):S43-S7.

2 Ünlü O, Zuily S, Erkan D. The clinical significance of antiphospholipid antibodies in systemic lupus erythematosus. Eur J Rheumatol. 2016;3(2):75.

3 Gehrs BC, Friedberg RC. Autoimmune hemolytic anemia. Am J Hematol. 2002;69(4) 258-71.

4 Hill A, Hill QA. Autoimmune hemolytic anemia. Hematol Am Soc Hematol Educ Program. 2018;2018(1):382-9.

5 Rottem M, Krause I, Fraser A, Stojanovich L, Rovensky J, Shoenfeld Y. Autoimmune hemolytic anaemia in the antiphospholipid syndrome. Lupus. 2006;15(7):473-7.

6 Berentsen S. How I manage patients with cold agglutinin disease. Br J Haematol. 2018; 181(3):320-30.

7 Berentsen S, Tjønnfjord GE. Diagnosis and treatment of cold agglutinin mediated autoimmune hemolytic anemia. Blood Rev. 2012; 26(3):107-15.
8 Kaushik S, Federle MP, Schur PH, Krishnan M, Silverman SG, Ros PR. Abdominal thrombotic and ischemic manifestations of the antiphospholipid antibody syndrome: CT findings in 42 patients. Radiology. 2001;218(3): 768-71.

9 Uthman I, Godeau B, Taher A, Khamashta M. The hematologic manifestations of the antiphospholipid syndrome. Blood Rev. 2008; 22(4):187-94

10 Cervera R, Piette JC, Font J, Khamashta MA, Shoenfeld Y, Camps MT, et al. Antiphospholipid syndrome: clinical and immunologic manifestations and patterns of disease expression in a cohort of 1,000 patients. Arthritis Rheum. 2002;46(4):1019-27.

11 Oku K, Atsumi T, Bohgaki M, Amengual O, Kataoka H, Horita T, et al. Complement activation in patients with primary antiphospholipid syndrome. Ann Rheum Dis. 2009;68(6): $1030-5$.

12 Chaturvedi S, Brodsky RA, McCrae KR Complement in the pathophysiology of the antiphospholipid syndrome. Front Immunol. 2019;10:449.
13 Berentsen S. Complement activation and inhibition in autoimmune hemolytic anemia: focus on cold agglutinin disease. Semin $\mathrm{He}-$ matol. 2018 Jul;55(3):141-9.

14 Ulvestad E, Berentsen S, Mollnes T. Acute phase haemolysis in chronic cold agglutinin disease. Scand J Immunol. 2001;54(1-2):239-42.

15 Berentsen S, Hill A, Hill QA, Tvedt THA, Michel M. Novel insights into the treatment of complement-mediated hemolytic anemias. TherAdvHematol.2019;10:2040620719873321.

16 Von Dem Borne AK, Engelfriet C, Reynierse E, Beckers D, Van Loghem J. Autoimmune haemolytic anaemia. VI. 51 chromium survival studies in patients with different kinds of warm autoantibodies. Clin Exp Immunol. 1973;13(4):561.

17 Reinstein E, Shoenfeld Y. Antiphospholipid syndrome and cancer. Clin Rev Allergy Immunol. 2007;32(2):184-7.

18 Berentsen S, Ulvestad E, Langholm R, Beiske K, Hjorth-Hansen H, Ghanima W, et al. Primary chronic cold agglutinin disease: a population based clinical study of 86 patients. Haematologica. 2006;91(4):460-6. 